\title{
Intrinsic Motives of Autonomy, Self-Efficacy, and Satisfaction Associated with Two Instances of Sustainable Behavior: Frugality and Equity
}

\author{
Víctor Corral-Verdugo*, Daniel González-Lomelí, Marisol Rascón-Cruz, Víctor O. Corral-Frías \\ University of Sonora, Hermosillo, Mexico \\ Email: *victorcorral@sociales.uson.mx
}

Received 6 April 2016; accepted 9 May 2016; published 12 May 2016

Copyright $@ 2016$ by authors and Scientific Research Publishing Inc.

This work is licensed under the Creative Commons Attribution International License (CC BY). http://creativecommons.org/licenses/by/4.0/

(c) (i) Open Access

\begin{abstract}
This paper explores the relationship between sustainable behavior, indicated by frugal and equitable actions, and three intrinsic motives: satisfaction, autonomy and self-efficacy. One-hundred and seventy-three undergraduates at a Mexican university responded to a questionnaire investigating their sustainable actions and the intrinsic repercussions derived from those actions. Using structural equations, a model is specified and tested, which reveals the presence of a higher-order factor (sustainable behavior) subjacent to a high and significant covariance between frugal and equitable behaviors. The resulting higher-order-factor, in turn, significantly predicts the report of feelings of satisfaction, autonomy, and self-efficacy. These findings are in line with the idea that sustainable behavior is to a good extent self-determined through the operation of intrinsic consequences, which instigate people's pro-social and pro-environmental actions.
\end{abstract}

\section{Keywords}

Frugality, Equity, Satisfaction, Autonomy, Self-Efficacy

\section{Introduction}

Sustainable behavior (SB) is "the set of deliberate and effective actions that result in the conservation of the natural and socio-cultural resources of the planet” (Corral-Verdugo, 2010). Actions aimed at protecting natural resources (pro-ecological) and other persons (altruistic), as well as the acts intended at achieving a decreased con-

${ }^{*}$ Corresponding author.

How to cite this paper: Corral-Verdugo, V., González-Lomelí, D., Rascón-Cruz, M., \& Corral-Frías, V. O. (2016). Intrinsic Motives of Autonomy, Self-Efficacy, and Satisfaction Associated with Two Instances of Sustainable Behavior: Frugality and Equity. Psychology, 7, 662-671. http://dx.doi.org/10.4236/psych.2016.75068 
sumption of products (frugal) and to treating others in a fair and unbiased way (equitable), are instances that characterize sustainable behavior. Evidence demonstrates the presence of high and significant interrelations between those types of actions, which reinforce the idea that a higher-order factor (sustainable behavior) integrates people’s diverse actions aimed at protecting their socio-physical environment (Corral-Verdugo, Frías, \& García, 2010). Most of the research in sustainable behavior has focused on pro-ecological and altruistic actions to the detriment of the study of frugal and equitable behaviors, which are the focus of this paper.

Frugal behavior implies a voluntary decreased consumption of products and a lightly way of living (Iwata, 2002). This kind of acting is essential for achieving the goals of sustainability since consumerism and waste of resources are at the basis of environmental degradation, and a frugal way of living opposes consumerism and waste. Frugal actions include the reuse of objects, the consumption of environmentally friendly products, a reduced purchase of accessories, walking or bicycling instead of driving, and living without luxuries, among others (de Young, 1996). Through these actions, individuals engage in behaviors that are intended at protecting their natural environment.

Equitable behavior, in turn, is conceived as fairly treating others, based on justice principles and avoiding bias or discrimination related to physical or demographic traits of persons when interacting with them. Equitable individuals help in empowering people in need to face the consequences of environmental degradation. This is achieved by guaranteeing a fair distribution of natural resources and social benefits for everybody, allowing equal opportunities for boys and girls in studying, and an equitable treatment to minorities and people of all socio-economic conditions, among others (Corral-Verdugo et al., 2010). The protection of the social environment is a target of individuals engaging in equitable actions.

Most of the current research in conservation psychology pays attention to antecedent variables that instigate sustainable behaviors; these include environmental attitudes, knowledge, skills, values, beliefs, and intention to act, among other factors that predispose individuals to act in favor of the socio-physical environment (Bamberg \& Möser, 2007). Contextual factors, either physical (weather, resources availability, technological tools) or normative (social rules, models, and conventions) are added to this list of antecedent variables (Corral-Verdugo, 2010). Yet, in spite of the significant explanatory power of models that include antecedent variables as predictors of sustainable behavior, it is necessary to consider that people also act motivated by the psychological consequences they obtain from their behavior (Lehman \& Geller, 2004). If those consequences are positive (i.e., pleasant, reinforcing), it is likely that they repeat their pro-environmental acting (Geller, 2002). The absence of those consequences usually results in a lack of motivation, which makes unlikely the engagement in environmentally-protective practices.

\section{Self-Determination Theory and Sustainable Behavior}

Self-determination Theory (SDT) is one of the theories that best synthesizes the relationship between positive behavioral consequences and the motivation for acting. SDT focuses on the degree to which an individual's behavior is self-motivated and self-determined. This is important for the psychology of sustainability because sustainable behavior is conceived as deliberate (i.e., intentional or self-determined) and incited by motivational factors (Corral-Verdugo, 2012). A number of studies -that will be further reviewed show that sustainablyoriented people experience gratifying psychological states that also might enhance self-determined pro-environmental actions. This is especially interesting because those states could make possible the emergence and maintenance of sustainable behavior without the need of extrinsic consequences and repeated interventions (de Young, 1993).

Feelings of satisfaction, self-efficacy, and autonomy are three commonly mentioned intrinsic consequences of behavior in the literature of SDT. Satisfaction is an intrinsic positive consequence emerging from a behavior that fulfills the expectations of an individual (Ryan \& Deci, 2000). Intrinsic satisfactions include interest, curiosity, joy, and sense of competency provided by behavior (de Young, 1996; Reeve, 1989; He, Greenberg, \& Huang, 2010).

Feelings of self-efficacy, in turn, derive from the belief a person holds regarding her/his own competency or capacity. When people engage in a task in an efficient way like, for instance, solving an environmental problemor achieve a goal, they experience the pleasant sensation of knowing that they are able or competent (de Young, 1996).

The sense of autonomy, finally, implies that people not only perceive their own competency but also that they ex- 
perience their behavior as self-determined (i.e., dependent from their will) in order to achieve a sustained and increased state of intrinsic motivation (Ryan \& Deci, 2000). This sense of autonomy is, clearly, also a positive feeling.

SDT establishes a difference between three categories of motivation to behave: amotivation, extrinsic motivation, and intrinsic motivation, (Ryan \& Deci, 2000). The three motivational types can be placed along a continuum reflecting the degree by which an individual is able to self-determine her or him.

Amotivation reflects a lack of contingency between the individual's behavior and the results these behaviors produce. In other words, amotivation predominates when a behavior does not produce a psychological consequence for the individual (Ryan \& Deci, 2000). A recent study (Carrus, Bonnes, Corral-Verdugo, Moser, \& Sinha, 2013) shows an example of amotivation in pro-environmentally acting, manifested in people's indifference towards water-conservation issues. Clearly, amotivated individuals do not have an incentive to behave in a sustainable way.

Extrinsic motivation (EM), in turn, refers to a large number of instrumental actions which a person engages in as a means to achieve goals; those goals usually represent rewards such as money or material gains, pleasure, social reputation, and so on. Extrinsic motives exert a powerful influence on sustainable behaviors, as the literature refers. For instance, conservationist actions make more likely the availability of natural resources, so that the individual can use them and enjoy their benefits. Many actions that conserve natural resources also produce savings or material gain (especially money) to those who practice them. Some examples of this are: the money a person is able to save from conserving water or energy, or the economic benefit that recycling provides to a number of individuals who sell products to recycling companies. An individual may be also benefited from tax reductions that are contingent to his/her environmentally protective actions. These are also extrinsic positive benefits (Lehman \& Geller, 2004). In one more example, altruism, as an instance of sustainable behavior, as well as pro-ecological behavior, are reinforced by the reputation gained by those who participate in the voluntary provision of goods and services to disadvantaged groups or in the conservation of the natural environment (Carpenter \& Meyers, 2007). Despite their undeniable benefit, extrinsic consequences show some drawbacks: the individual receiving them depends on external sources in obtaining the reward; i.e. if there is no available source, the benefit does not appear. One more problem is that if the extrinsic consequence is removed the sustainable behavior is extinguished (Lehman \& Geller, 2004). In addition, the events that are used as extrinsic consequences are more related to anti-ecological (Corral-Verdugo, 2010) or antisocial (Gifford, 2007) behaviors than to sustainable actions. For instance, the provision of material rewards like money is rather an instigator of consumerism than a predictor of frugality, while social status reinforces inequity rather than a fair distribution of benefits (equity). Likewise, it has been found that materialistic people (those who are prone to experimenting extrinsic consequences) are less inclined to environmental conservation and more oriented to ambition (money, power) and the exploitation of natural resources (Crompton \& Kasser, 2009). Therefore, the promotion of intrinsic consequences of sustainable behavior is preferred over the use of the extrinsic ones (Ryan \& Deci, 2000; Crompton \& Kasser, 2009).

Intrinsic motivation (IM) represents the most self-determined behavior. IM implies engaging in activities because the intrinsic value they possess, because they are naturally interesting and fun, i.e., by its inherent appeal. Solid evidence exists showing the existence of intrinsic motives associated to the practice of sustainable behaviors. Psychological wellbeing (PWB), a concept focusing on the development of personal capacities and growth (Ryff, 1989), seems to be an intrinsic repercussion of sustainable practices. A study (Corral-Verdugo, Montiel, Sotomayor, Frías, Tapia, \& Fraijo, 2011) found that people reporting more pro-social and pro-environmental activities informed also higher levels of psychological wellbeing. Happiness and the pleasure it contains, might also function as an intrinsic consequence of sustainable behavior. Other authors (Brown \& Kasser, 2005; Bechtel \& Corral-Verdugo, 2010) have also reported that pro-ecologically-oriented people tend to be happier, while a more recent study (Corral-Verdugo, Mireles, Tapia, \& Fraijo, 2011) added altruistic, frugal, and equitable behaviors to the list of sustainable behaviors that are benefited with happy feelings. The intrinsic benefits of sustainable behavior also include motives associated to self-determination: One of them is the satisfaction generated from pro-environmentally acting (Iwata, 2002). This satisfaction has also been conceived as a source of behavioral self-regulation, which, along with a feeling of self-efficacy, generates intrinsic positive consequences that lead people to behave in a pro-ecological manner (Hernández, Tabernero, \& Suárez, 2010). It has also been reported that the practice of pro-ecological actions promotes a state of competence motivation (similar to self-efficacy), produced by the perception of one's own ability (i.e., knowing than one acted effectively and pro-environmentally) (de Young, 1996). In more of this, a study showed that autonomous individuals report 
more stable proenvironmental attitudes over time, a higher involvement in environmental behaviors, and higher levels of well-being (Villacorta, Koestner, \& Lekes, 2003). No study has reported the simultaneous presence of feelings of satisfaction, self-efficacy, and autonomy associated to sustainable acting.

Intrinsic and extrinsic motivations are of particular interest for environmental psychologists and educators, since, evidently, an amotivated person will hardly engage in sustainable actions. The study of the intrinsic positive consequences of sustainable behavior might help in explaining why people keep themselves in assisting other individuals even if this implies sacrificing time, effort and money; also, why many persons get involved in the apparently annoying and sacrificing activities of environmental protection (Lindenberg \& Steg, 2007). The answer to these questions may be that, ultimately, pro-sustainably oriented individuals obtain more personal (intrinsic) benefits than it is supposed from their pro-social and pro-environmental acting. Evidence exists showing that intrinsic consequences might be, at least, as powerful as the extrinsic reinforcement in inducing sustainable actions (Carpenter \& Meyers, 2007). Studying such consequences could provide ways of developing effective and automatic incentives for sustainable acting.

The aim of this study was to test the idea that sustainable behavior, indicated by frugal and equitable actions, is significantly associated to three positive intrinsic consequences: the feelings of satisfaction, self-efficacy and autonomy. No previous research investigating the relationship between equitability and those intrinsic consequences is detected neither is the association between frugal behaviors and simultaneously those three intrinsic consequences. We administered instruments assessing those psychological factors to a sample of undergraduates, and analyzed their responses within a structural model, as detailed in the following section.

\section{Method}

\subsection{Participants}

One-hundred-seventy-three undergraduate students at a public university in Hermosillo, a middle-sized northwestern Mexican city (population $=800,000$ ), were the participants in this study. They were 83 females and 90 males; their age ranged from 20 to 30 years (mean $=22.39$; $\mathrm{SD}=1.64$ ); their average family monthly income was $=\$ 1500.00$ U.S. Dlls $(S D=2046.00)$ and they were coursing their last two years at school.

\subsection{Instruments}

We assessed Frugality in actions such as buying the strictly necessary, the reuse of clothing, taking meals at home, etc., which were reported using a 5-point likert-options of response $(0=$ totally agree..., $4=$ totally disagree); this instrument was designed by Corral-Verdugo \& Pinheiro (2004). Equity, was measured with a scale developed by Corral-Verdugo, García, Castro, Viramontes, \& Limones (2010), which included ten items indicating behaviors such as providing equal educational opportunities for girls and boys, and treating the rich and the poor as equals, etc., using response options from 0 (totally disagree) to 4 (totally agree).

We also utilized a Spanish version of the General Self-efficacy scale developed by Baessler \& Schwarzer (1996), which includes 10 items in a likert-type, four-point scale of response $(0=$ completely agree, $1=$ parcially disagree, 2 = parcially agree, 3 = totally agree). The scale evaluates the stable feeling of personal competency in handling a variety of daily and stressful situations. Six items from the Autonomy dimension of Ryff's (1989) Psychological Wellbeing scale were also used. This instrument, also considering a four-point scale of response, assessed people's sense of own competency and self-determination. Finally, a scale of Satisfaction was developed by the authors of this paper, to assess how much the practice of sustainable actions fulfill the expectations of an individual in terms of their feeling glad, pleased and satisfied. This scale also utilized the likert-type system of responding above described for the self-efficacy and autonomy scales.

\subsection{Procedure}

The instruments were administered at the participants' classrooms. Participants were debriefed by telling them the aims of the study and their informed consent to participate was obtained. None refused to collaborate with the study. The administration of the scales took about twenty minutes.

\subsection{Data Analysis}

Results were analyzed by using univariate statistics (means, standard deviations) in every scale’s items. The in- 
ternal consistency of the scales was also analyzed calculating their Cronbach’s alphas. Interrelations among latent variables were estimated, first, in a confirmatory factor analysis that produced estimates of covariances among the five first-order factors analyzed, and then within a structural equation model, using three parcels by studied construct. Five first-order factors were constructed: 1) frugality; 2) equity, which were the indicators of a second order-factor of "sustainable behavior"; 3) autonomy; 4) self-efficacy; and 5) satisfaction. The specified model assumed that the second-order factor would significantly affect the three intrinsic motives assessed.

\section{Results}

Table 1 and Table 2 show the univariate statistics of the used scales, and their internal consistency. Chronbach's alphas varied from .68 to .86, indicating an acceptable reliability. Since the range of responses to the scales of frugality and equity varied from 0 to 4 it can be observed that the respondents reported higher levels of equity (mean $=3.20$ ) than of frugality (mean $=2.60$ ). The levels of feelings of self-efficacy were the highest (mean $=2.32$ ) among the studied intrinsic motives, followed by the feelings of satisfaction (2.13) and autonomy (mean $=1.71)$. The Cronbach's alphas of the scales ranged from .68, the minimum, to .86, the maximum, indicating an adequate level of internal consistency.

Table 3, in turn, exhibits the obtained covariances among the five first-order factors. Significant correlations $(p<0.05)$ resulted in all but two cases: those were the covariances between frugality and self-efficacy, and autonomy and satisfaction, which resulted nonsignificant.

Figure 1 represents the results of the structural model specified to assess the relations between sustainable behavior and happiness. Since the factor loadings connecting the first-order factors (frugality, equity, autonomy, self-efficacy, satisfaction) with their corresponding indicators were high and significant $(p<0.05)$ we concluded that the used instruments possess convergent construct validity. Also, the frugality and equity factors saliently and significantly converged on the second order construct of sustainable behavior, as anticipated. This is revealed by the value and statistical significance $(p<0.05)$ of their factor loadings. The structural coefficients connecting sustainable behavior to autonomy (0.37), self-efficacy (0.46), and satisfaction (0.45) were salient and significant as we also expected. Sustainable behavior explained $14 \%$ of autonomy's variance, $21 \%$ of self-efficacy, and 20\% of satisfaction. The goodness of fit indicators of the model are reported in the bottom of Figure 1. They seem to indicate that the data support the hypothesized model of relations.

Table 1. Means and reliability of the frugality and equity scales $(\mathrm{N}=173)$.

\begin{tabular}{|c|c|c|c|}
\hline Scale/Items & $M$ & $S D$ & $\alpha$ \\
\hline Frugality & 2.60 & & .68 \\
\hline Does not buy a new car if old is functional & 2.76 & 1.36 & \\
\hline Wears same clothing & 2.80 & 1.21 & \\
\hline Wouldn't buy jewelry & 3.10 & 1.19 & \\
\hline Buys lots of shoes (reversed) & 2.44 & 1.21 & \\
\hline Buys more food than needed (reversed) & 2.32 & 1.19 & \\
\hline Uses most earnings for buying clothing (reversed) & 2.43 & 1.17 & \\
\hline Always takes meals at home & 2.81 & 1.20 & \\
\hline Rather walks than drives & 2.66 & 1.39 & \\
\hline Reuse notebooks and paper & 2.35 & 1.44 & \\
\hline Lives lightly & 2.33 & 1.26 & \\
\hline Equity & 3.20 & & .74 \\
\hline My partner (wife/husband; girlfriend/boyfriend) has the same right as I to make decisions about anything & 3.48 & 1.11 & \\
\hline I treat all my fellows as my equals, regardless of their social origin & 3.51 & .97 & \\
\hline In my home, children have the same right as adults to Make important decisions for family & 2.53 & 1.29 & \\
\hline In my family, men and women have the same obligations on cleanliness of the house & 3.03 & 1.24 & \\
\hline I treat indigenous people the same way I treat other people & 3.26 & 1.16 & \\
\hline My treatment for poor people is the same I have with the rich ones & 3.34 & 1.02 & \\
\hline In my family, girls have the same opportunity to study than boys & 3.31 & 1.17 & \\
\hline
\end{tabular}


Table 2. Means and reliability of the autonomy, self-efficacy and satisfaction scales $(\mathrm{N}=173)$.

\begin{tabular}{|c|c|c|c|}
\hline Scale/Items & $M$ & $S D$ & $\square \alpha$ \\
\hline Autonomy & 1.71 & & 0.82 \\
\hline His/her decisions are not influenced by what others do & 1.60 & 1.15 & \\
\hline Tends to worry about what other people think of him/her & 1.63 & 1.03 & \\
\hline Being happy is more importante that having others' approval & 1.41 & 1.07 & \\
\hline Difficult to voice opinions in controversial matters & 1.84 & 1.00 & \\
\hline Tend to be influenced by people with strong opinions & 2.05 & 1.05 & \\
\hline S(he) often changes her/his decisions if his/her friends or family disagree & 1.78 & 1.02 & \\
\hline Self-efficacy & 2.32 & & 0.86 \\
\hline Can't find the way to get what (s)he wants even if someone opposes him/her & 2.30 & 0.88 & \\
\hline Can solve difficult problems if s(he) efforts enough & 2.58 & 0.67 & \\
\hline It's easy to persist in what I am aimed at & 2.40 & 0.77 & \\
\hline Is confidente that (s)he could handle unexpected events & 2.30 & 0.76 & \\
\hline Thanks to his/her quialities and resources (s)he can overcome unforeseen situations & 2.27 & 0.82 & \\
\hline When in trouble (s)he can stay quiet because (s)he has the skills to handle difficult situations & 2.12 & 0.82 & \\
\hline Whatever it comes, usually (s)he is able to handle it & 2.27 & 0.80 & \\
\hline Can solve most problems if (s)he efforts enough & 2.44 & 0.82 & \\
\hline In difficult situations, (s)he usually figure out what to do & 2.27 & 0.86 & \\
\hline When facing a problem, s(he) usually thinks of alternatives to solve it & 2.27 & 0.89 & \\
\hline Satisfaction & 2.13 & & 0.77 \\
\hline Feels satisfaction every time (s)he conserves water & 2.09 & 1.04 & \\
\hline Separating trash makes him/her fel satisfied & 1.63 & 1.05 & \\
\hline Turning off the lights others leave generates satisfaction & 2.15 & 1.00 & \\
\hline Every time (s)he helps a homeless, feels satisfaction & 1.87 & 1.06 & \\
\hline Feels satisfaction after helping elderly to cross the street & 2.24 & 0.96 & \\
\hline Feels satisfaction livin without luxuries & 1.98 & 0.96 & \\
\hline Feels satisfied treating poor people equal than the rich & 2.27 & 0.92 & \\
\hline Feels satisfied sharing home reposabilities & 2.50 & 1.45 & \\
\hline Feels satisfied with relations with others & 2.36 & 0.93 & \\
\hline Glad of the image others have of her/him & 2.17 & 0.99 & \\
\hline Taking care of my Family pleases him/her & 2.22 & 0.99 & \\
\hline
\end{tabular}

Table 3. Covariance matrix of sustainable-behavior and intrinsic-motive factors (results from a confirmatory factor analysis).

\begin{tabular}{|c|c|c|c|c|c|}
\hline & 1 & 2 & 3 & 4 & 5 \\
\hline 1. Frugality & - & & & & \\
\hline 2. Equity & $0.59^{* *}$ & - & & & \\
\hline 3. Autonomy & $0.28^{*}$ & $0.36^{*}$ & - & & \\
\hline 4. Self-efficacy & 0.14 & $0.45^{*}$ & $0.35^{*}$ & - & \\
\hline 5. Satisfaction & $0.25^{*}$ & $0.45^{*}$ & 0.03 & $0.35^{*}$ & - \\
\hline
\end{tabular}
${ }^{*} p<.05$.

\section{Discussion}

As predicted, in our study, frugal and equitable practices were significantly related to intrinsic motives. The more a person reported to engage in a reduced-consumption lifestyle and to treat others in a fair and unbiased 


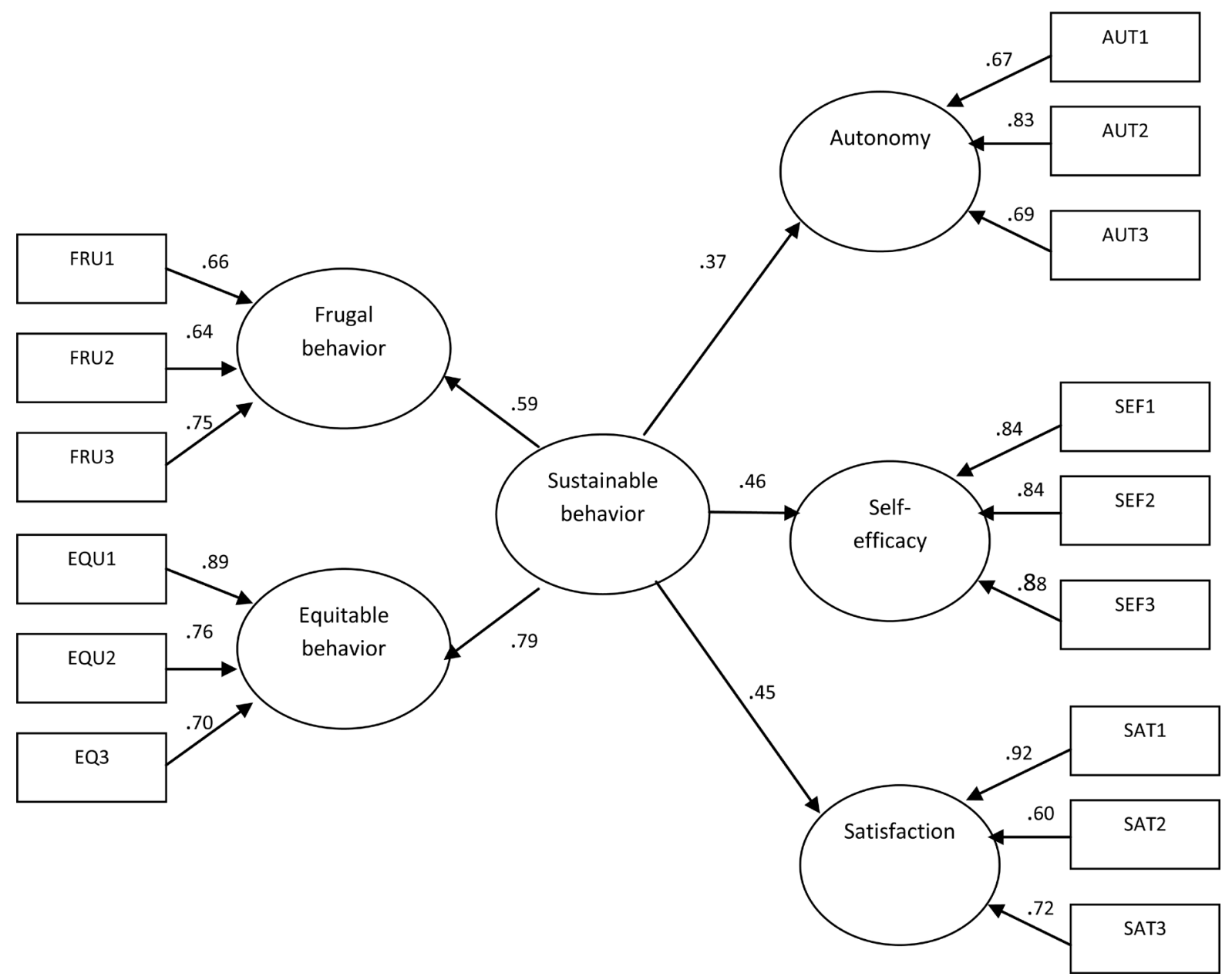

Figure 1. Structural relations between sustainable behavior (frugality, equity) and the intrinsic motives of autonomy, self-efficacy, and satisfaction. Goodness of fit: $X^{2}=305.45(181 \mathrm{gl}), p<0.0001 ; N N F I=0.97, C F I=0.98 ; R M S E A=0.03$. Autonomy's $R^{2}=14$; Self-efficacy's $R^{2}=21$; Satisfaction's $R^{2}=20$.

way, the more (s)he reported feelings of autonomy, self-efficacy and satisfaction. Although these intrinsic motives had been studied as correlates of some sustainable practices, to our knowledge, no report investigating the association of those motives with equitable behavior - an instance of sustainable behavior - had been so far produced. In addition, the association between sustainable actions and these three intrinsic motives simultaneously reported was neither found in the literature.

The aim of the study reported here was to test the idea that a person that behaves in a sustainable way was more likely to experience intrinsic motives, manifested as feelings of autonomy, self-efficacy, and satisfaction. These three motives were mentioned in antecedent studies as likely instigators of pro-environmental actions. Accordingly, a series of research reports had shown the influence of feelings of self-efficacy on the practice of sustainable behaviors (de Young, 1996; Corral-Verdugo, 1996; Iwata, 2001). The findings in our own study replicated the previous reports. According to de Young (2000), self-efficacy feelings initiate a virtuous cycle wherein the more the motivation obtained from sensing than one was pro-environmentally competent, the more one's engagement in sustainable practices. Corral-Verdugo (1996), in turn, assured that the intrinsic motives of competence (or self-efficacy), and the corresponding pro-environmental skills that were displayed, went together in the shaping of pro-environmental competency. This competency very likely generated more self-efficacy motivation and further sustainable acting.

Also according to de Young (2000), an individual that frequently engages in sustainable practices experiences an intrinsic satisfaction from his/her pro-environmental competency, and also from the very experience of performing an action in favor of the environment. This satisfaction has also been conceived as a source of beha- 
vioral self-regulation, which, along with the feelings of self-efficacy, is an intrinsic positive consequences that incite people to act in a pro-sustainable way. In this regard, a study (Hernández et al., 2010) found that the satisfaction obtained from getting involved in conservation behaviors associated highly and significantly to sustainable acting. Our results are in line with the findings of these previous studies, showing that the sense of self-efficacy is higher in people who report higher involvement in equitable and frugal actions.

In regard to autonomy, it is pertinent mentioning that sustainable acting is by definition, self-determined behavior, which means that these kinds of conduct falls under the control of the individual's will (Bamberg, 2002; Eriksson, Garvil, \& Nordlund, 2008). In this sense, autonomy should be an intrinsic motive associated to an individual's sustainable acting because through his/her self-determination (s)he decides to act, choosing a course of pro-environmental action, even if (s)he faces options that opposes her/his pro-sustainable decision. If this is true, the practice of sustainable actions should increase the sense of autonomy of those engaging in sustainable behaviors, as a research report suggests (Villacorta et al., 2003). This idea seems to be also supported by the findings of the present study.

In summary, a frugal and equitable person seems to obtain satisfaction, and feelings of autonomy and self-efficacy from his/her pro-environmental and pro-social acting. Since these intrinsic consequences are potential automatic instigators of further sustainable behaviors these results are encouraging. They indicate that the mere practice of frugal and equitable actions may result in positive mental states that promote and sustain conservationist and pro-social behaviors.

An exemption to this conclusion seems to be the nonsignificant association obtained between frugality and self-efficacy (covariance $=0.14, p>0.05$ ), implying that the studied participants did not experience competence motivation (de Young, 1996) from their anti-consumerist practices. This is an unexpected finding that deserves replication. The other non-significant covariance resulted between the intrinsic motives of autonomy and satisfaction, seemingly indicating that feeling satisfaction has nothing to do with own sense of autonomy. The fact that these three factors share the category of intrinsic motives makes this unexpected finding to appear as an anomaly that also deserves further replication.

Frugal and equitable behaviors are essential for achieving a sustainable-oriented way of living. Their opposite practices_-consumerism and inequity—are acknowledged to stand at the basis of the current environmental crisis (Oskamp, 2000; Ehrlich \& Ehrlich, 2004). Interventions based on extrinsic consequences (material and social reinforcement) aimed at reducing consumerist and inequitable behaviors are difficult to implement because extrinsic consequences are rather instigators of unsustainable actions than incentives to conserve the environment (Crompton \& Kasser, 2009). Providing people with material rewards, like money, to instigate frugality may be counterproductive since material incentives are more easily associated with consumerism. In other words, extrinsic, material consequences are more effective in instigating waste of resources than austere practices. In a related way, trying to reinforce equitable behaviors with social status (reputation) is more difficult than rewarding inequity with such social extrinsic consequence because social status reinforces inequity rather than a fair distribution of benefits (Crompton \& Kasser, 2009). Therefore, the main effort should be invested in developing strategies to connect these sustainable behaviors with their intrinsic consequences.

Kurz (2002) and Corral-Verdugo \& Domínguez (2011) recommend a number of strategies to produce such connection: 1) Providing public information regarding the expected intrinsic benefits (positive psychological states) the individual would obtain if (s)he engages in sustainable practices; 2) Making sustainable behavior an "affordable" practice to facilitate people's engagement and further obtaining intrinsic consequences; 3) Including the practice of sustainable actions as a part of the school curriculum, which would lead to the daily experiencing of positive psychological consequences; 4) Increasing the effort invested in research regarding non-studied intrinsic consequences of sustainable behavior; 5) Increasing people's ability to resist consumerist and materialistic messages, encouraging them to act in concordance with intrinsic goals.

The above described strategies require a combination of scientific, educational, political and legal effort. The scientific community has to be involved in providing reliable knowledge regarding what positive consequences of sustainable behavior are to be expected by people, the actions these consequences are most connected with, and how they operate; also, this community is expected to design and test interventional programs of social and educational nature. The educational sector has the task of incorporating sustainability as an integral part of the school curriculum, making students to engage in daily pro-environmental practices (as a part of their training). The legal system and its derived social policies are in charge of facilitating a significant investment in research and education; passing legal regulations to modify the current materialistically-oriented way of living, and re- 
warding sustainable practices at the individual and group levels.

Some limitations of this study should be mentioned. Although some of the demographic characteristics of the studied sample correspond to those of the general population, we cannot conclude that our participants are representative of the Mexican population they were extracted from. Therefore, a further study considering a more representative sample of the general population should be conducted. Besides, in this study, self-reports were used as a method assessing sustainable actions and people's self-reported behavior is not necessarily identical to their actual behaviors. Another limitation of the study has to do with the non-experimental design used in our research. Although we, along with most authors in the area, assume that autonomy, satisfaction and self-efficacy are intrinsic consequences of being sustainable we cannot conclude that the significant covariation between these intrinsic motives and sustainable behavior proves a causal relationship, with the former being the effect and the latter the cause. Therefore, an experimental study could be required in order to verify the assumption of a causal relationship (asking, for instance, participants to engage in sustainable actions and subsequently assess changes in their intrinsic-motivational levels). In any case, the important fact is that the connection between acting sustainably and intrinsic motivation seems to be established and environmental educators may take advantage of it in their interventional strategies.

Although everybody depends on the gratifying consequences that external forces provide after engaging in prosocial and proecological actions, we now know that it is necessary to supplement the external control of people's behavior, helping them to become self-determined, responsible individuals. In this sense, the area of study and intervention concerning the role played by the intrinsic consequences of sustainable behavior is especially interesting because its novelty and promising applications in the transition towards a more sustainable society.

\section{References}

Baessler, J., \& Schwarzer, S. (1996). Evaluación de la autoeficacia: Adaptación española de la escala de Autoeficacia General [Evaluation of Self-Efficacy: Spanish Adaptation of the General Self-Efficacy Scale]. Ansiedad y Estrés, 2, 1-8.

Bamberg, S., \& Möser, G. (2007). Twenty Years after Hines, Hungerford, and Tomera: A New Meta-Analysis of Psycho-Social Determinants of Pro-Environmental Behavior. Journal of Environmental Psychology, 27, 14-25. http://dx.doi.org/10.1016/j.jenvp.2006.12.002

Bamberg, S. (2002). Effect of Implementation Intentions on the Actual Performance of New Environmentally Friendly Behaviors-Results of Two Field Experiments. Journal of Environmental Psychology, 22, 399-411. http://dx.doi.org/10.1006/jevp.2002.0278

Bechtel, R. B., \& Corral-Verdugo, V. (2010). Happiness and Sustainable Behavior. In V. Corral, C. García, \& M. Frías (Eds.), Psychological Approaches to Sustainability (pp. 433-450). New York: Nova Science Publishers.

Brown, K. W., \& Kasser, T. (2005). Are Psychological and Ecological Well-Being Compatible? The Role of Values, Mindfulness, and Lifestyle. Social Indicators Research, 74, 349-368. http://dx.doi.org/10.1007/s11205-004-8207-8

Carpenter, J., \& Meyers, C. K. (2007). Why volunteer? Evidence on the Role of Altruism, Reputation, and Incentives. IZA Discussion Paper, 3021. http://www.gate.cnrs.fr/IMG/pdf/Carpenter.pdf

Carrus, G., Bonnes, M., Corral-Verdugo, V., Moser, G., \& Sinha, J. (2013). Social-Psychological and Contextual Predictors of Sustainable Water Consumption. In V. Corral, C. García, \& M. Frías (Eds.), Psychological Approaches to Sustainability (pp. 43-60), New York: Nova Science Publishers.

Corral-Verdugo, V., \& Pinheiro, J. (2004). Aproximaciones al estudio de la conducta sustentable [Approaches to the Study of Sustainable Behavior]. Medio Ambiente y Comportamiento Humano, 5, 1-26.

Corral-Verdugo, V., \& Domínguez, L. (2011). El rol de los eventos antecedentes y consecuentes en la conducta sustentable [The Role of Antecedent and Consequent Events in Sustainable Behavior]. Revista Mexicana de Análisis de la Conducta, 37, 9-29. http://dx.doi.org/10.5514/rmac.v37.i2.26137

Corral-Verdugo, V. (1996). A Structural Model of Reuse and Recycling Behavior in Mexico. Environment and Behavior, 28, 665-696. http://dx.doi.org/10.1177/001391659602800505

Corral-Verdugo, V. (2010). Psicología de la Sustentabilidad [Psychology of Sustainability]. Mexico City: Trillas.

Corral-Verdugo, V. (2012). The Positive Psychology of Sustainability. Environment, Development \& Sustainability, 14, 651-666. http://dx.doi.org/10.1007/s10668-012-9346-8

Corral-Verdugo, V., Frías, M., \& García, C. (2010). Introduction to the Psychological Dimensions of Sustainability. In V. Corral, C. García, \& M. Frías (Eds.), Psychological Approaches to Sustainability (pp. 3-18). New York: Nova Science Publishers. 
Corral-Verdugo, V., García, C., Castro, L., Viramontes, I., \& Limones, R. (2010). Equity and Sustainable Lifestyles. In V. Corral, C. García, \& M. Frías (Eds.), Psychological Approaches to Sustainability (pp. 185-204). New York: Nova Science Publishers.

Corral-Verdugo, V., Mireles, J., Tapia, C., \& Fraijo, B. (2011). Happiness as a Correlate of Sustainable Behavior. A Study of Proecological, Frugal, Equitable and Altruistic Actions That Promote Subjective Wellbeing. Human Ecology Review, 18, 95-104.

Corral-Verdugo, V., Montiel, M., Sotomayor, M., Frías, M., Tapia, C., \& Fraijo, B. (2011). Psychological Wellbeing as Correlate of Sustainable Behaviors. International Journal of Hispanic Psychology, 4, 31-44.

Crompton, T., \& Kasser, T. (2009). Meeting Environmental Challenges: The Role of Human Identity. WWF-UK. http://assets.wwf.org.uk/downloads/meeting_environmental_challenges_the_role_of_human_identity.pdf

De Young, R. (1993). Changing Behavior and Making It Stick: The Conceptualization and Management of Conservation Behavior. Environment and Behavior, 25, 485-505. http://dx.doi.org/10.1177/0013916593253003

De Young, R. (1996). Some Psychological Aspects of a Reduced Consumption Lifestyle: The Role of Intrinsic Satisfaction and Competence Motivation. Environment \& Behavior, 28, 358-409. http://dx.doi.org/10.1177/0013916596283005

De Young, R. (2000). Expanding and Evaluating Motives for Environmentally Responsible Behavior. Journal of Social Issues, 56, 509-526. http://dx.doi.org/10.1111/0022-4537.00181

Ehrlich, P., \& Ehrlich, A. (2004). One with Niniveh. Politics, Consumption and the Human Future. Washington DC: Shearwater Books.

Eriksson, L., Garvill, J., \& Nordlund, A. M. (2008). Interrupting Habitual Car Use: The Importance of Car Habit Strength and Moral Motivation for Personal Car Use Reduction. Transportation Research Part F: Traffic Psychology and Behaviour, 11, 10-23. http://dx.doi.org/10.1016/j.trf.2007.05.004

Geller, E. S. (2002). The Challenge of Increasing Pro-Environment Behavior. In R. B. Bechtel, \& A. Churchman (Eds.), Handbook of Environmental Psychology (pp. 525-540). New York: Wiley.

Gifford, R. (2007). Environmental Psychology: Principles and Practice (4th ed.). Colville, WA: Optimal Books.

He, H., Greenberg, S., \& Huang, E. (2010). One Size Does Not Fit All: Applying the Transtheoretical Model to Energy Feedback Technology Design. Proceedings of the 28th International Conference on Human Factors in Computing Systems, Atlanta, 10-15 April 2010, 927-936. http://dx.doi.org/10.1145/1753326.1753464

Hernández, B., Tabernero, C., \& Suárez, E. (2010). Psychosocial Motivations and Self-Regulation Processes That Activate Environmentally Responsible Behavior. In J. Valentín, \& L. Gámez (Eds.), Environmental Psychology: New Developments (pp. 109-126). New York: Nova Science Publishers.

Iwata, O. (2001). Attitudinal Determinants of Environmentally Responsible Behavior. Social Behavior and Personality, 29, 183-190. http://dx.doi.org/10.2224/sbp.2001.29.2.183

Iwata, O. (2002). Coping Style and Three Psychological Measures Associated with Environmentally Responsible Behavior. Social Behavior and Personality, 30, 661-669. http://dx.doi.org/10.2224/sbp.2002.30.7.661

Kurz, T. (2002). The Psychology of Environmentally Sustainable Behavior: Fitting Together Pieces of the Puzzle. Analysis of Social Issues and Public Policy, 2, 257-278. http://dx.doi.org/10.1111/j.1530-2415.2002.00041.x

Lehman, P. H., \& Geller, E. S. (2004). Behavior Analysis and Environmental Protection: Accomplishments and Potential for More. Behavior and Social Issues, 13, 13-32. http://dx.doi.org/10.5210/bsi.v13i1.33

Lindenberg, S., \& Steg, L. (2007). Normative, Gain and Hedonic Goal Frames Guiding Environmental Behavior. Journal of Social Issues, 63, 117-137. http://dx.doi.org/10.1111/j.1540-4560.2007.00499.x

Oskamp, S. (2000). A Sustainable Future for Humanity? American Psychologist, 55, 496-508.

http://dx.doi.org/10.1037/0003-066X.55.5.496

Reeve, J. (1989). The Interest-Enjoyment Distinction in Intrinsic Motivation. Motivation and Emotion, 13, 83-104. http://dx.doi.org/10.1007/BF00992956

Ryan, R., \& Deci, E. (2000). Self-Determination Theory and the Facilitation of Intrinsic Motivation, Social Development, and Well-Being. American Psychologist, 55, 68-78. http://dx.doi.org/10.1037/0003-066X.55.1.68

Ryff, C. (1989). Happiness Is Everything, or Is It? Explorations on the Meaning of Psychological Well-Being. Journal of Personality and Social Psychology, 57, 1069-1081. http://dx.doi.org/10.1037/0022-3514.57.6.1069

Villacorta, M., Koestner, R., \& Lekes, M. (2003). Further Validation of the Motivation toward the Environment Scale. Environment \& Behavior, 35, 486-505. http://dx.doi.org/10.1177/0013916503035004003 